\title{
Should psychiatrists support CPA, guidelines and routine outcome measurement?
}

\author{
Paul Lelliott
}

The Psychiatric Bulletin recently published a letter from a consultant psychiatrist (Dickinson, 1996) warning of the potential dangers attending the implementation of systematic approaches to care (e.g. CPA), clinical practice guidelines (CPGs) and routine outcome measurement (e.g. Health of the Nation Outcome Scales-HoNOS). The letter was precipitated by the author attending a session at the College Summer Meeting, organised by the College Research Unit which is playing a role in all three developments.

The fears expressed by the letter's author can be summarised as:

(1) These developments being misused by others, presumably by non-clinicians. For example, HoNOS scores might be used "nationally to sort out the best from the worst services".

(2) Such misuses creating perverse incentives, leading for example to the falsification of HoNOS scores to paint an over-rosy picture of a service's performance.

(3) CPGs encouraging unrealistic expectations, among patients, carers and presumably purchasers, that treatment will always be "perfect" with litigation resulting if this is not the case.

(4) Standardisation of practice through CPGs stifling innovation and leading to loss of the flexibility needed to tailor care to the needs of individuals.

(5) An increase in documentation and paperwork at the expense of face-to-face time with patients.

Unfortunately, no easy reassurance can be given that these fears are groundless, particularly if psychiatrists are not leading these initiatives at both national and local level. Therefore, assuming that the Ministerial decree requiring CPA implementation, and the pressure from the same direction for CPGs and HoNOS, are insufficient reasons in themselves, why should psychiatrists support these developments?

The most powerful argument is that psychiatrists as a profession, and the College as its representative body, are committed to improving the quality of psychiatric practice and therefore of care for our patients. Psychiatrists would be failing in this commitment if they ignored the growing evidence of the inconsistency and inappropriateness of much medical activity and, while defending their own practice from what they see as interference by less qualified or less competent people, they in effect deny that the average standard needs to be, and can be, improved. Even good clinicians might learn something. This is why the medical profession welcomed the introduction of clinical audit. Some of the other reasons are discussed below.

\section{Politics}

The inclusion of mental lliness as one of the five key areas in the Health of the Nation has undoubtedly given political prominence to mental health services, which have traditionally been the poor relations of acute services. While attention from politicians is not always welcome it does ensure that pressure is applied from above for a fair distribution of resources. HoNOS was conceived as the means of measurement of the first Health of the Nation Target and so is integral to the success of the initiative.

\section{Contracting}

Commissioners of services, who are likely to survive whatever the result of the next General Election, will continue to expect evidence of effectiveness from services they purchase. This might be in the form of evidence that treatment processes are right (i.e. that people with certain conditions are given the appropriate treatment) or that patient outcomes are what should be expected from a good service. Commissioners think it reasonable to expect such information and also that they should compare local outcomes with those achieved elsewhere.

Given this inevitability, psychiatrists should be working to develop guidelines which incorporate 
the evidence for, and therefore justify, what are often expensive and protracted interventions. This will become more important as the primary card led NHS develops and secondary care mental health services negotiate for protection of services for the "severely mentally ill" in the face of great demand for services for the larger number of the "less severely ill".

In the new NHS, psychiatry is competing for resources with other medical specialities. The widespread introduction of routine outcome measurement should give it an advantage over specialities which rely on simple process data. There will always be a danger that such information. "in the wrong hands" will be misused; it is therefore the responsibility of psychiatrists to educate purchasers, and politicians, in the interpretation of outcomes data and the complex factors which might account for differences between services.

\section{Public expectation}

Although psychiatry remains a relatively low-risk speciality at a time when litigation for medical negligence is on the increase, the public's perception appears to be that it is failing the patients who are most at risk (or who pose most risk). Frequent and sensationalist news stories highlight apparent mistakes in risk assessment, miscommunications between workers and failure to maintain contact with patients. CPA, and supervision registers, were introduced as a direct result of enquiries into such apparent failures of community care. I imagine that a poll of lay people would indicate strong support for the good practice principles of CPA, including the formal recording of needs assessments and written care plans.

\section{Patient benefits}

There is considerable variation between doctors in the treatments applied to the same conditions. In some instances a proportion of this variation is due to inappropriate practice which results in suboptimal outcomes for the patient. The delay between research providing conclusive evidence of effectiveness of a new inter-vention and that intervention being incorporated into routine practice can be many years. The corollary applies when interventions are found to be ineffective. There is now evidence that practice guidelines, which should incorporate evidence from recent and systematic reviews, do lead to measurable improvements in patient care if implemented with approprlate educational strategles (Grtmshaw \& Russell, 1993).

In summary, CPA, HoNOS and CPGs are new technologies with the potential to further the aims of psychiatrists to develop services which better deliver care in dispersed community settings, argue for resources in the face of competing priorities and improve the quality and consistency of care. Their development reflects changes in the NHS which have introduced market concepts, greater accountability and more transparency.

These changes seem to have been accepted, and in some cases embraced, by colleagues from other disciplines, and in management. While doctors have an important role in questioning developments which might hamper patient wellbeing, we must not behave like Canute. A recent survey conducted by the College Research Unit found that managers in more than $40 \%$ of 62 trusts reported difficulties in engaging psychiatrists in local CPA activity; no other clinical group had been as antagonistic (report available from the College Research Unit). In many of these trusts a major clinical service reorganisation seemed to have been made with little active input from psychiatrists.

Put starkly, psychiatrists have two options; either we resist such developments and risk becoming marginalised within our own services or we take the lead and ensure that the potential benefits of new technologies such as HoNOS and CPGs are realised and the potential misuses, including unnecessary bureaucracy, are minimised. Success will not be achieved easily because, as with any new technology, proficiency will only come with training, practice and supervision.

\section{References}

Dickinson, M. J. (1996) HoNOS, CPA, CPGs \& Co. Psychiatric Bulletin, 20, 119.

Grimshaw, J. M. \& RUSSEU. I. T. (1993) Effect of clinical guidelines on medical practice: a systematic review of rigorous evaluations. Lancet, 342. 1317-1322.

Paul Lelliott, Director, Royal College of Psychiatrists' Research Unit, 11 Grosuenor Crescent, London SWIX 7EE 